\title{
Instrumental cirúrgico
}

\section{Surgical instrumentation}

\author{
Takachi Moriya ${ }^{1}$, Yvone A Morais V de Andrade Vicente², Maria de Fátima G Sorita Tazima²
}

\begin{abstract}
RESUMO
Para a execução de cada uma das etapas do procedimento cirúrgico utilizam-se instrumentos distintos e são necessários ordem e método para permitir ao cirurgião executar o procedimento com precisão e rapidez. Para isso, o instrumental cirúrgico deve ser listado e preparado com antecedência, de acordo com o tipo de cirurgia a ser realizada e preferência do cirurgião.
\end{abstract}

Palavras-chave: Instrumentos Cirúrgicos. Material Cirúrgico. Técnica Cirúrgica. Procedimentos Cirúrgicos Operatórios.

O procedimento cirúrgico se realiza através de três operações fundamentais: a diérese dos tecidos, a hemostasia dos vasos sangrantes e a síntese que possibilita a cicatrização por primeira intenção. Para a execução de cada uma destas etapas utilizam-se instrumentos distintos e necessita-se de ordem e método para permitir ao cirurgião executar o procedimento com precisão e rapidez. Por isso o instrumental cirúrgico deve ser listado, preparado com antecedência, de acordo com o tipo de cirurgia a ser realizada e da preferência do cirurgião e, na sala cirúrgica, devem ser dispostos ordenadamente sobre uma mesa, de maneira padronizada, de acordo com as etapas da cirurgia.

A diérese consiste na divulsão dos tecidos e permite a exposição dos órgãos estruturas afetadas, utilizando-se bisturis, tesouras e ruginas (Figura 1)

A hemostasia visa estancar, temporária ou de- finitivamente, o sangramento dos vasos seccionados durante a diérese, com pinças de Halsted, de Kelly, de Crile, de Rochester e de Moyniham (Figura 2).

A síntese visa reconstruir e restituir a integridade das estruturas, órgãos e tecidos que foram operados usando-se porta agulhas, pinças anatômicas e dente de rato, agulhas e fios cirúrgicos (Figura 3).

Em quase todos os procedimentos, os instrumentos, para realizar tanto a diérese, como também a hemostasia e a síntese, são semelhantes, porém procedimentos específicos podem necessitar de instrumentos auxiliares, como em cirurgias urológicas, proctológicas, cardíacas, torácicas e neurológicas, etc. Os instrumentos auxiliares mais utilizados são os afastadores de Farabeuf, de Doyen, de Gosset, de Finocchietto, de Volkmann, pinça de Backaus, de Allis, de Kocher e de Mixter (Figura 4).
1. Docente. Disciplina de Cirurgia Vascular e Endovascular. Departamento de Cirurgia e Anatomia da Faculdade de Medicina de Ribeirão Preto da USP.

2. Docente. Disciplina de Cirurgia Pediátrica. Departamento de Cirurgia e Anatomia da Faculdade de Medicina de Ribeirão Preto da USP.
Correspondência: Departamento de Cirurgia e Anatomia da FMRP-USP. Hospital das Clínicas da FMRP-USP - 9a andar Avenida Bandeirantes, 3900 14048-900 - Ribeirão Preto/SP

Artigo recebido em 20/07/2010 Aprovado para publicação em 24/02/2011 


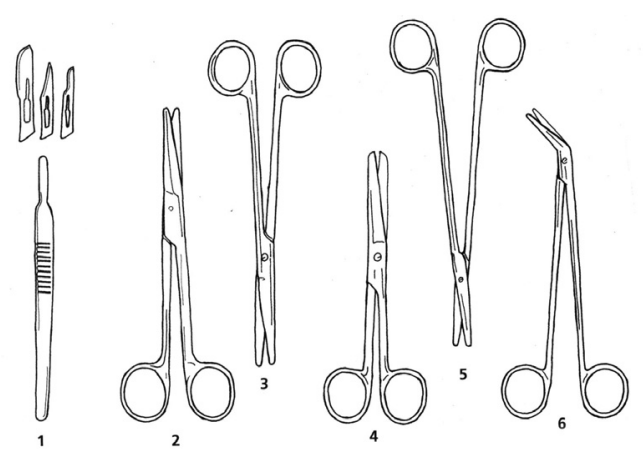

Figura 1. Material utilizado para diérese: (1) bisturi, (2) tesoura de Mayo curva, (3) tesoura de Mayo reta, (4) tesoura para fios, (5) tesoura de Metzenbaum e (6) tesoura de Potts.
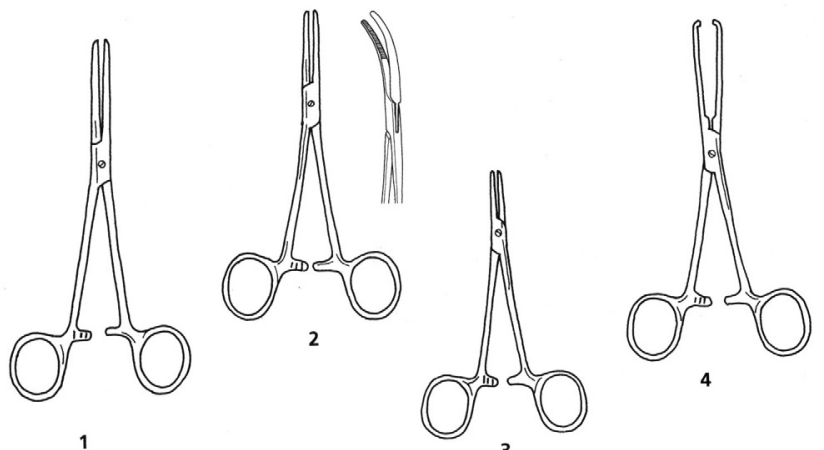

Figura 2: Material de preensão e hemostasia: (1) pinça de Kelly, (2) pinça de Halsted curva, (3) pinça de Halsted reta, (4) pinça de Allis

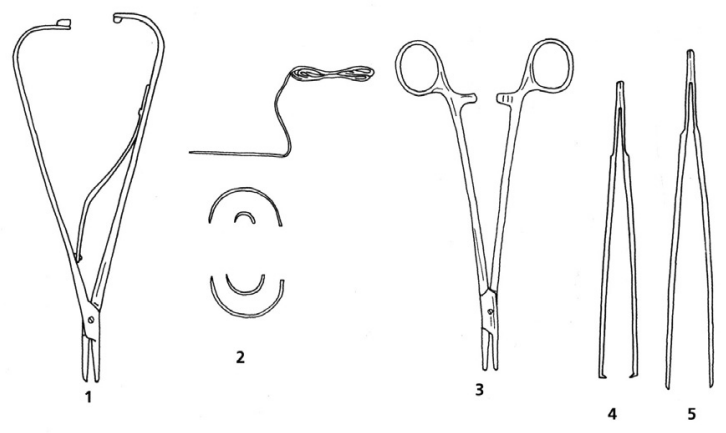

Figura 3: Material de síntese: (1) porta agulhas de Mathiew, (2) agulhas, (3) porta agulhas de Hegar, (4) pinça dente de rato e (5) pinça anatõmica.

\section{Mesa Cirùrglca}

Pra a exposição dos instrumentos, dvide-se a mesa utilizada em quatro quadrantes, para comportar os instrumentos de diérese, de síntese, de hemostasia e os instrumentos auxiliares. Por exemplo, para se

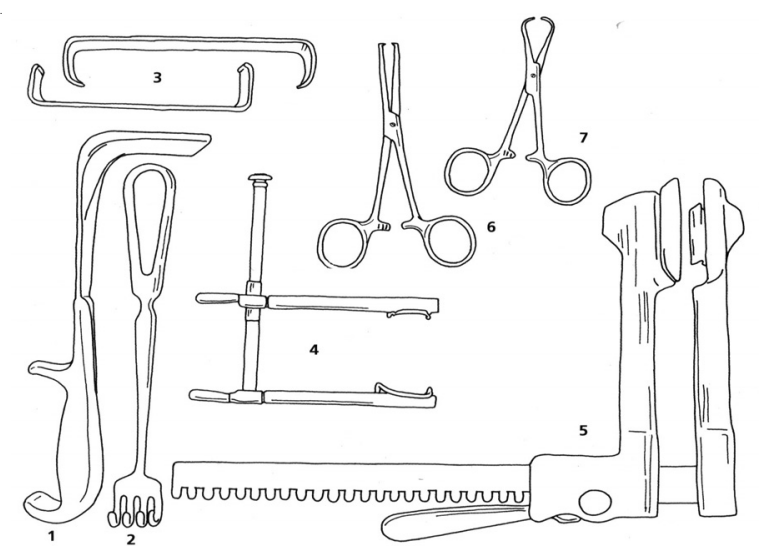

Figura 4: Material de exposição e preensão: (1) afastador de Doyen, (2) afastador de Volkmann, (3) afastador de Farabeuf, (4) afastador de Gosset, (5) afastador de Finocchietto, (6) pinça de Kocher e (7) pinça de Backaus.

realizar uma laparotomia supra umbilical, executada por um cirurgião destro, o instrumentador se posiciona à esquerda do paciente e dispõem os instrumentos, na mesa, como mostram as Figuras 5 e 6.

\begin{tabular}{|cc|}
\hline $\begin{array}{c}\text { Instrumentos } \\
\text { auxiliares }\end{array}$ & $\begin{array}{c}\text { Instrumentos } \\
\text { de síntese }\end{array}$ \\
\hline $\begin{array}{c}\text { Instrumentos } \\
\text { de hemostasia }\end{array}$ & $\begin{array}{c}\text { Instrumentos } \\
\text { de diérese }\end{array}$ \\
\hline
\end{tabular}

Instrumentador

Figura 5: Disposição do instrumental na mesa de cirurgia

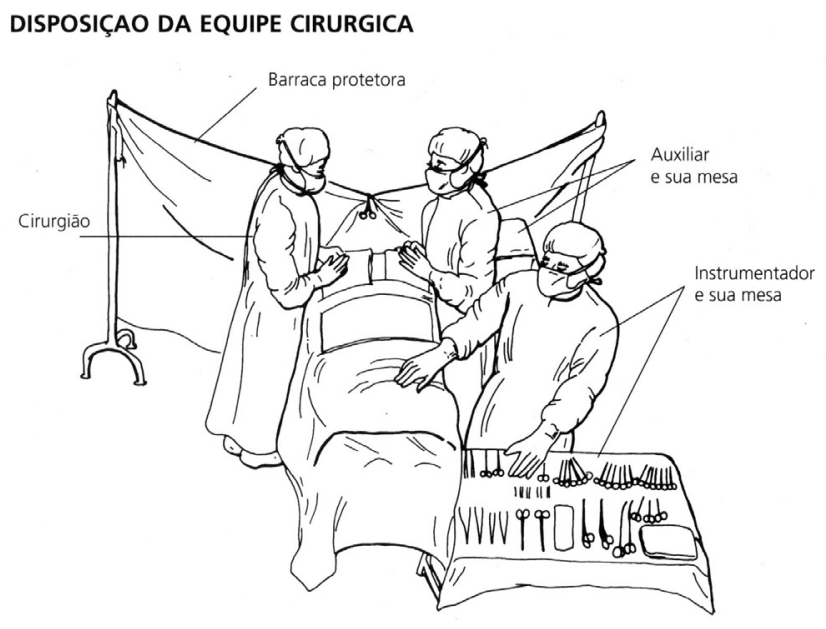

Figura 6: Disposição dos instrumentos e da equipe cirúrgica em uma laparotomia supra-umbilical realizada por cirurgião destro. 
Esta disposição facilita a instrumentação, pois, o procedimento cirúrgico consiste de uma sequiência padronizada de etapas e, portanto, pode-se acompanhar com precisão o tempo cirúrgico, executado pelo cirurgião e escolher qual o quadrante da mesa a ser abordado.

\section{Sondas e drenos}

\section{Definição}

A drenagem cirúrgica é a técnica para remover coleções líquidas ou gasosas de uma cavidade serosa, feria ou abscesso por meio de simples abertura ou através de colocação de dreno ou qualquer com que se assegura a saída dos fluidos, através da pele ou mucosas. É uma técnica invasiva e cruenta.

\section{Classificação} aspectos:

A drenagem pode ser classificada sob vários

\section{Finalidade:}

\section{a. Diagnóstica}

A drenagem diagnóstica tem objetivo medir o volume, o ritmo de saída de líquidos e gases, a fim de determinar a existência e a permanência de uma afecção interna, como exemplo a drenagem da cavidade pleural no caso de hemorragia interna onde podemos diagnosticar a existência e a permanência da mesma e decidir por uma intervenção.

\begin{tabular}{|c|c|}
\hline Finalidade & $\begin{array}{l}\text { diagnóstica } \\
\text { preventiva } \\
\text { curativa }\end{array}$ \\
\hline Mecanismo & $\begin{array}{l}\text { expontânea } \\
\text { cirúrgica }\end{array}$ \\
\hline Manutenção & $\begin{array}{l}\text { simples } \\
\text { com aspiração }\end{array}$ \\
\hline Local & $\begin{array}{l}\text { abdominal } \\
\text { torácico } \\
\text { cervical, etc }\end{array}$ \\
\hline Plano & $\begin{array}{l}\text { superficial } \\
\text { profundo }\end{array}$ \\
\hline Material & $\begin{array}{l}\text { tubo semi-rígido } \\
\text { lâmina flexível } \\
\text { tubo rígido (trocarte) }\end{array}$ \\
\hline Duração & $\begin{array}{l}\text { curta } \\
\text { prolongada }\end{array}$ \\
\hline
\end{tabular}

A drenagem diagnóstica tem objetivo medir o volume, o ritmo de saída de líquidos e gases, a fim de determinar a existência e a permanência de uma afecção interna, como exemplo a drenagem da cavidade pleural no caso de hemorragia interna onde podemos diagnosticar a existência e a permanência da mesma e decidir por uma intervenção cirúrgica corretiva.

\section{b. Preventiva}

É uma forma de drenagem das mais usadas, sendo feita sempre em cirurgias onde haja ou se suspeita de infecção, quando os líquidos que se formam no local ou o estado geral do paciente, como cirurgia de pâncreas com abscessos localizados.

\section{c. Curativa}

A drenagem curativa tem o objetivo de eliminar o líquido residual enclausurado, habitualmente pus, permitindo que o organismo promova a recuperação daquela região atingida evitando assim a disseminação do processo. Por exemplo, a drenagem de abscesso subfrênico.

\section{Mecanismo}

O líquido preso dentro de cavidades orgânicas, com aumento progressivo do seu volume, pode drenar espontaneamente para outras regiões ou para o exterior do organismo, por aumento da pressão do líquido ou por necrose tecidual. A drenagem cirúrgica é feita quando o processo não responde ao tratamento medicamentosos (antibióticos) ou quando atingir grandes proporções.

\section{Manutenção}

A drenagem é simples quando o líquido é eliminado livre e espontaneamente pelo orifício de drenagem e por aspiração é necessário aplicar uma pressão negativa contínua ou intermitente no dreno, a fim de forçar e facilitar a saída da secreção.

\section{Local}

Classifica-se em função da região anatômica do corpo humano a ser drenada: cerebral, cervical, torácica, abdominal etc. A drenagem de cada região anatômica exige materiais e técnicas específicas.

\section{Plano}

As drenagens podem ser superficiais e ou profundas. 


\section{Material}

Os tubos semi-rígidos de plástico ou de borracha podem ser usados em cavidades orgânicas (espaço pleural) e em canalículos orgânicos como vias biliares. As lâminas flexíveis de borracha e drenos de penrose estão indicadas para a drenagem de regiões menores e com pequena produção de líquidos, como em drenagem superficial de parede abdominal.

\section{Duração}

Ela pode ser de curta duração, como a retirada de liquido ascítico, ou prolongada por dias como no caso da drenagem de vias biliares ou da cavidade pleural.

\section{Técnlcas de drenagem}

A drenagem deve obedecer a certos princípios para facilitar o escoamento e evitar complicações como obstrução ou contaminação de outros setores:

1. Colocar o dreno em posição de maior declive para líquidos

2. Colocar o dreno em posição de maior aclive para o ar

3. O ponto de penetração para acesso ao local deve ficar o mais próximo possível deste

4. O dreno deve ser sempre colocado fora da incisão primária

5. O dreno deve ser adequado ao tipo e ao volume do material a ser eliminado

6. O dreno deve ficar em posição a mais confortável possível ao paciente

7. O orifício de passagem do dreno deve ser de dimensão proporcional ao mesmo

8. O dreno deve sempre ser adequadamente fixado à pele

9. A drenagem é regra geral nas cirurgias de tórax

10. A drenagem é exceção nas cirurgias abdominais (exemplos: cirurgia das vias biliares extra-hepáticas, cirurgias do pâncreas, coleções purulentas em espaços teciduais)

\section{Principais tipos de drenos:}

Os drenos podem ser de qualquer material como um tubo, gaze, desde que assegure a saída das secreções.

1. Dreno tubular multi-perfurado

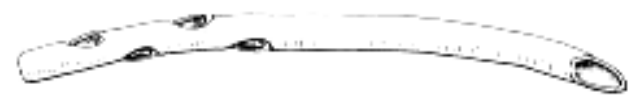

2. Dreno tubular laminado

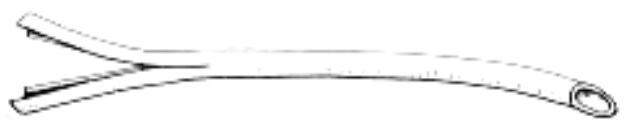

3. Sonda de Malecot - utilizada em gastrostomia

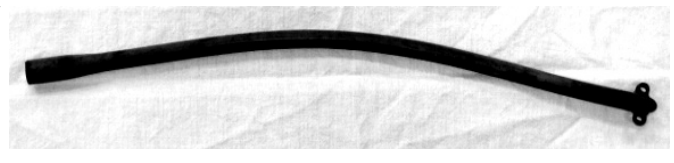

4. Dreno T de Kehr - utilizada para drenagem de vias biliares

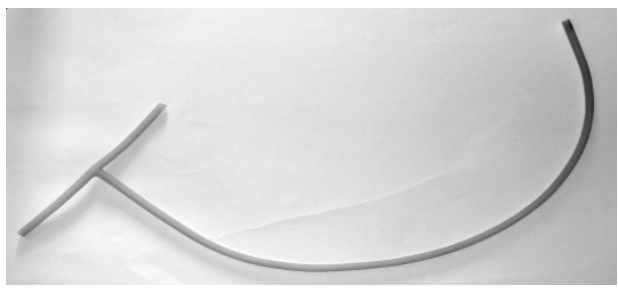

5. Dreno de Penrose

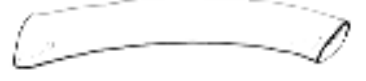

6. Dreno de Penrose com gaze no seu interior

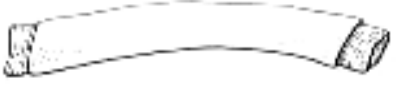

7. Sonda retal

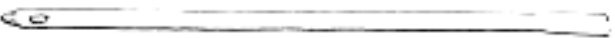

8. Sonda de Nelaton

9. Sonda de Fouchet - utilizada para lavagem esofágica ou lavagem intestinal por sifonagem

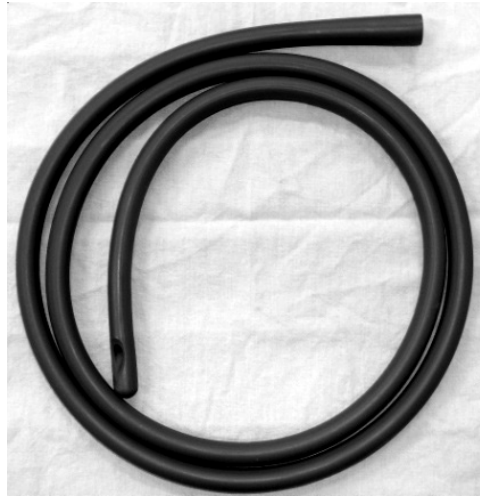


10. Sonda de Foley: A ponta proximal é arredondada e tem um balão que é inflado com solução estéril de água destilada ou soro fisiológico, tem dupla ou tripla luz, sendo uma para injetar líquido dentro do balão, a outra para drenar a urina e a de três vias tem uma terceira luz para introduzir alguma solução na bexiga. $\mathrm{Na}$ ponta distal tem duas ou três pontas, sendo uma a que insufla o balão, a outra drena urina e nas de três vias, uma que injeta solução.

11. Sonda de Levine ou sonda
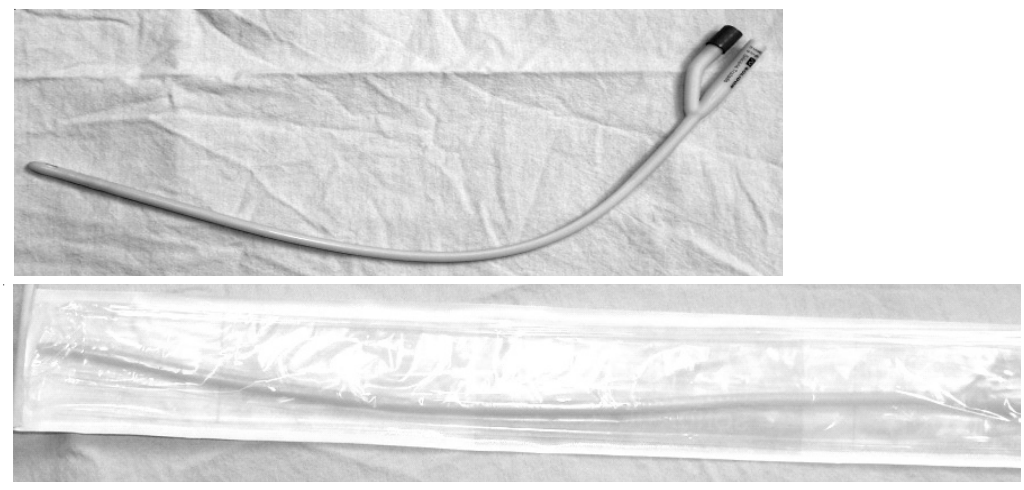

Sondas Foley de 2 vias.

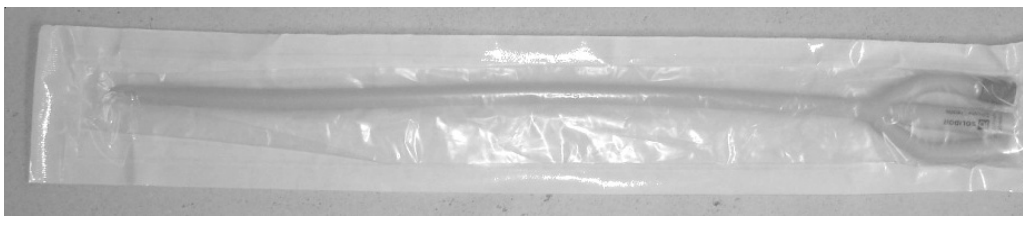

Sonda de Foley 3 vias. nasogástrica. A sonda é introduzida pela narina e posicionada no estômago. Técnica: deve se medir a distância entre a ponta do nariz e o lóbulo da orelha do paciente e deste até o apêndice xifóide, para medir o comprimento da sonda a ser introduzida, com a finalidade de lavar o estomago, fazer aspiração de secreções e sangue coletado e para alimentação artificial.

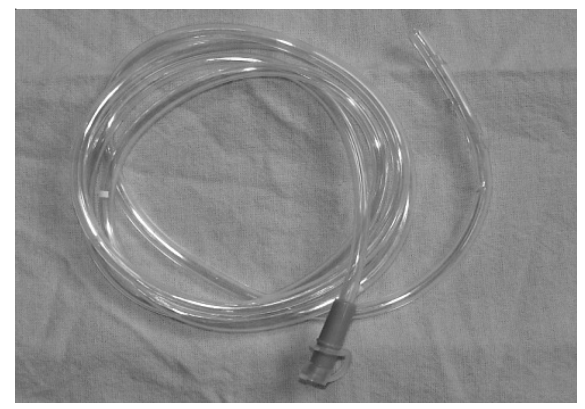

13. Sonda oro-traqueal de Rusch.

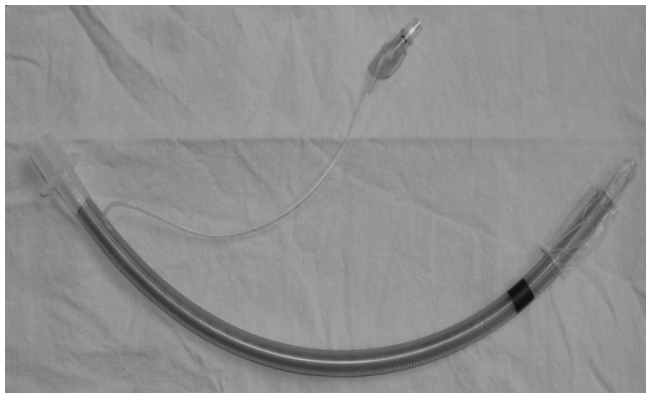

14. Sonda orotraqueal de entubação seletiva de brônquios de Carlens

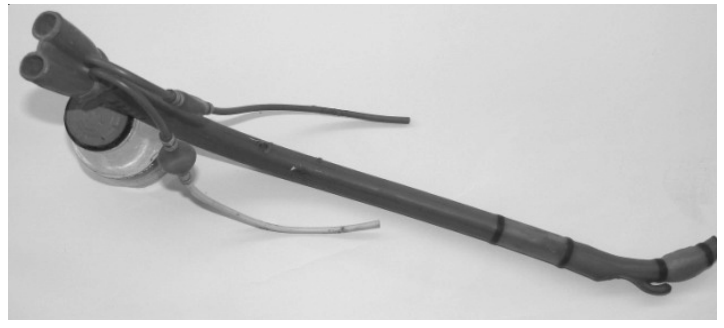

15. Sonda oro-traqueal de entubação seletiva de brônquios de Robert Shaw
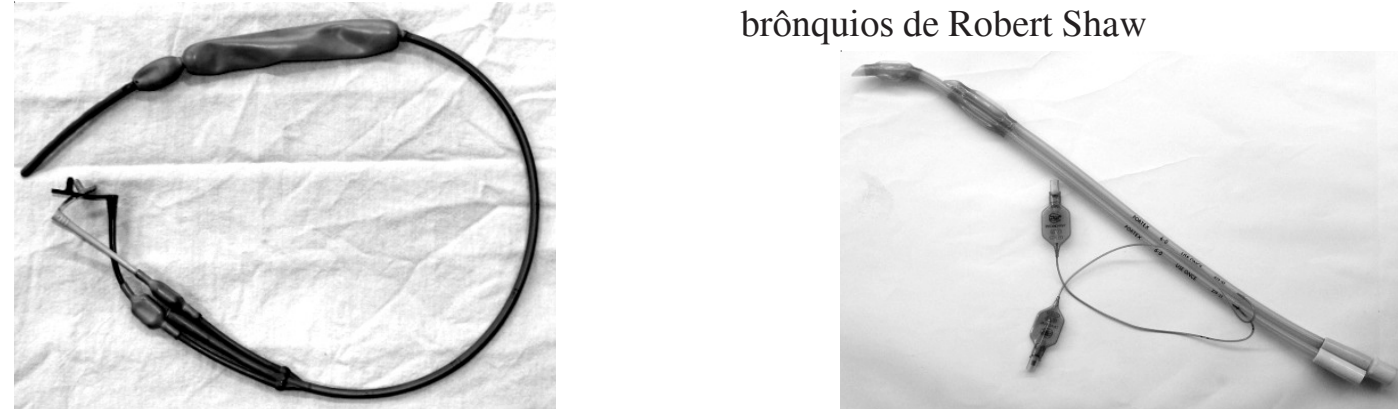
16. Sonda de aspiração

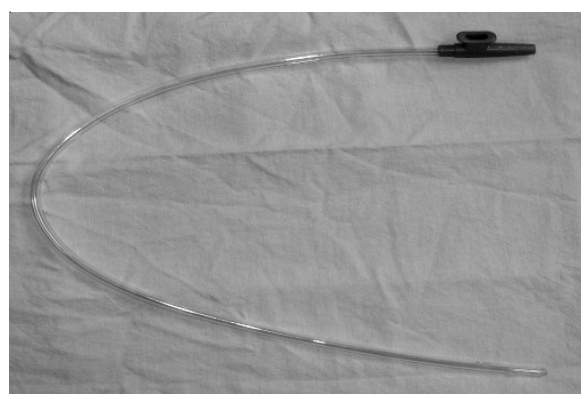

17. Sonda naso-entérica - introduz-se pelo nariz e posiciona-se no intestino delgado e serve para alimentação enteral.

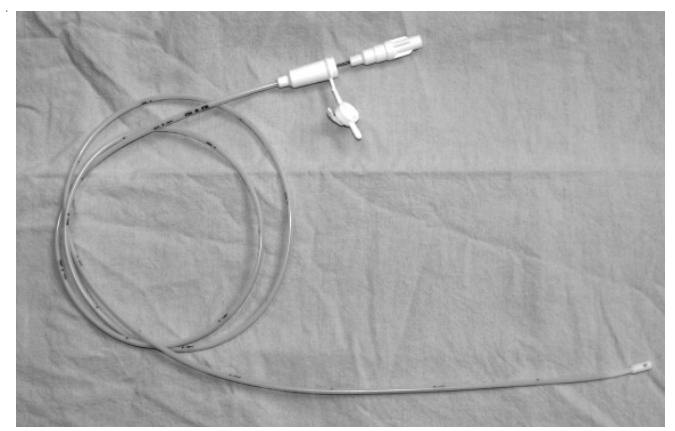

18. Trocartes

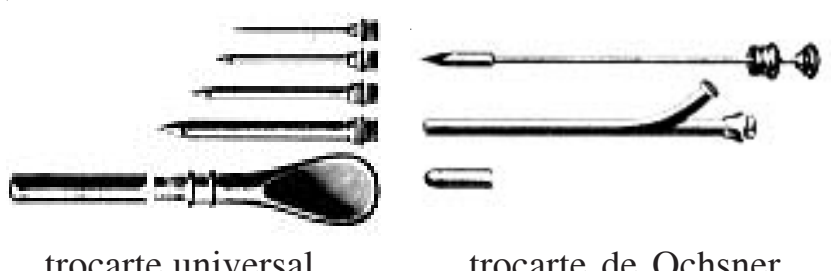

trocarte universal

trocarte de Ochsner

\section{Classifficação de drenos e sondas}

\section{A- Quanto à forma:}

1- Tubular

a. rígido e metálico: trocater.

b. semi-rígido: Malecot, nelaton, retal, dreno de tórax, dreno $\mathrm{T}$ de Kehr

2- Laminar

a. simples: dreno de Penrose.

b. misto: dreno de Penrose com gaze

\section{B- Quanto ao material confeccionado:}

1- plástico: dreno de tórax, sonda nasogátrica, etc.

2- metal: trocarte universal .
3- borracha (látex ou silicone): sonda de Malecot, nelaton, dreno de penrose, dreno $\mathrm{T}$ de Kehr.

4- outros: gase, fios.

\section{Fios cirúrgicos e nós}

Os fios cirúrgicos, durante a síntese, fixam ou contém as estruturas orgânicas divulsionadas ou cortadas, na diérese. Para isso, utilizam-se agulhas, adaptadas e desenhadas de acordo com as características, tanto dos tecidos a serem suturados, como dos fios escolhidos.

Um fio ideal deve ter, baixo custo, grande resistência à tração e torção, ausência de reação tecidual, calibre fino e regular, esterilização fácil e também ser mole, flexível, pouco elástico e resistente á esterilização.

Pode-se classificar os fios em mono e multifilamentares, quanto ao número de filamentos dos quais são feitos. Os multi-filamentares dividem-se em torcidos, trançados e trançados com revestimento.

Quanto ao material confeccionado, eles se classificam em absorvíveis e inabsorvíveis. Os absorvíveis podem ser de origem animal, como o catgut simples ou então de origem vegetal. Os fios de origem vegetal podem se revestidos, como o polyvicril ou sem revestimento, como o dexon e o vicryl. Os inabsorvíveis também podem ter origem animal como a seda trançada, ou vegetal como o algodão, ou então de origem sintética como o mononylon, prolene e mersilene. Existem também os fios metálicos, de aço inoxidável, como o aciflex.

Os fios cirúrgicos são vendidos de acordo com um comprimento padrão, de 45 a $140 \mathrm{~cm}$, e cada fabricante, para cada fio identifica, na embalagem, as especificações do fio que ela contém, tais como o material de que é feito, comprimento, se está acoplado a uma agulha e que tipo de agulha contém. Os fios são comercializados já esterilizados e com data de validade para sua utlização.

As embalagens de fios cirúrgicos podem conter um único fio ou vários.

Os fios podem estar acoplados a uma agulha, para facilitar seu uso. Neste caso, o calibre da agulha deve ser semelhante ao calibre do fio. Existem fios com uma e com duas agulhas.

O calibre dos fios cirúrgicos é identificado pela quantidade de números zero, $1-0 ; 2-0 ; 3-0 ; 4-0 ; .$. etc. Quanto maior o número de zeros menor é o calibre do fio, até $12-0$, o de diâmetro $0,001 \mathrm{~mm}$. 
Como o fio pode se comportar como corpo estranho e prejudicar a cicatrização, é aconselhável escolher o calibre do fio de acordo com a resistência, o tipo de estrutura a ser suturada e a tensão entre as bordas da ferida..

A escolha do tipo de fio, se absorvível ou inabsorvivel, depende da resistência e do tempo da manutenção da sutura até a sua total cicatrização. Deve-se escolher um fio inabsorvível, quando houver a necessidade da manutenção de sua resistência por um período maior do que 2 a 3 semanas ou quando a reação inflamatória deve ser a menor possível.

A experiência, o conhecimento das estruturas a serem operadas, da técnica cirúrgica e da biologia da ferida e da cicatrização, aliados ao bom senso, determinam qual o melhor fio a ser utilizado.

Os quadros I e II mostram os tipos, a composição, a origem e a resistência tênsil.

\section{Quadro I: Fios absorvíveis}

\begin{tabular}{|c|c|c|c|}
\hline Fio & Composição & Origem & Resistência 11 \\
\hline \multirow[t]{3}{*}{ Categute simples } & Proteína COLAGENO & Animal Torcido & $1 \mathrm{dia}=100 \%$ \\
\hline & & & 7 dias $=40 \%$ \\
\hline & & & 14 dias $=5 \%$ \\
\hline \multirow[t]{4}{*}{ Categute cromado } & Proteína - COLÁGENO & Animal Torcido & $1 \mathrm{dia}=100 \%$ \\
\hline & & & 7 dias $=65 \%$ \\
\hline & & & 14 dias $=40 \%$ \\
\hline & & & 21 dias $=10 \%$ \\
\hline \multirow[t]{4}{*}{ Vicryl } & Poliglactina 910 & Sintético Trançado & $1 \mathrm{dia}=100 \%$ \\
\hline & Glicolida 90\% / Lactida 10\% & & 14 dias $=65 \%$ \\
\hline & Cobertura de poliglactina $370(50 \%)$ & & 21 dias $=30 / 40 \%$ \\
\hline & + estearato de cálcio (50\%) & & 28 dias $=5 / 10 \%$ \\
\hline \multirow[t]{5}{*}{ Vicryi rápida absorção } & Poliglactina 910 & Sintético Trançado & $1 \mathrm{dia}=100 \%$ \\
\hline & Glicolida 90\% / Lactida 10\% & & 3 dias $=81 \%$ \\
\hline & Cobertura de poliglactina $370(50 \%)$ & & 5 dias $=57 \%$ \\
\hline & + estearato de cálcio (50\%) & & 7 dias $=53 \%$ \\
\hline & & & 14 dias $=0 \%$ \\
\hline PDS 11 & polimerização da DIOXANONA & Sintético Mono & $1 \mathrm{dia}=100 \%$ \\
\hline \multirow[t]{4}{*}{ Monocryl } & Poliglecaprone 25 & Sintético Mono & $1 d=100 \%$ \\
\hline & Glicolida 75\% / Caprolactona 25\% & & $7 d=50 / 60 \%$ \\
\hline & & & $14 d=20 / 30 \%$ \\
\hline & & & $21 \mathrm{~d}=0 \%$ \\
\hline
\end{tabular}




\begin{tabular}{lllll}
$\begin{array}{l}\text { Quadro II: Fios não absorvíveis } \\
\text { Fio }\end{array}$ & Composição & Origem & Absorção \\
\hline Polycot & $\begin{array}{l}\text { 70\% filamentos de poliéster } \\
+30 \% \text { fibras longas de algodão }\end{array}$ & Sintético 1 + Vegetal & Torcido & $\begin{array}{l}\text { Permanece } \\
\text { encapsulado }\end{array}$ \\
Aciflex & Aço Inox 316 L & Mineral & Mono & $\begin{array}{l}\text { Permanece } \\
\text { encapsulado }\end{array}$ \\
Mersilene & Poliéster & Sintético & Trançado & $\begin{array}{l}\text { Permanece } \\
\text { encapsulado }\end{array}$ \\
Mersilene 10-0 & Poliéster & Sintético & Mono & $\begin{array}{l}\text { Permanece } \\
\text { encapsulado }\end{array}$ \\
Ethibond & Poliéster, com cobertura & Sintético & Trançado & $\begin{array}{l}\text { Permanece } \\
\text { encapsulado }\end{array}$ \\
Ethibond com teflon & Poliéster, com cobertura & Sintético & Trançado & $\begin{array}{l}\text { Permanece } \\
\text { encapsulado }\end{array}$ \\
Prolene & Polipropileno & Sintético & Mono & $\begin{array}{l}\text { Permanece } \\
\text { encapsulado }\end{array}$ \\
\hline
\end{tabular}

\section{Nós cirúrgicos}

O nó em cirurgia assume um papel importante, pois durante a síntese ou a hemostasia, as estruturas são suturadas ou aproximadas, utilizando-se agulha e fio e, depende do nó, que fixa e estabiliza a sutura, o sucesso da sua cicatrização.

Os nós usados, em cirurgia, seguem os mesmos princípios de um nó comum. Porém, durante o procedimento cirúrgico, muitas vezes o cirurgião atua em um campo restrito, ou então existe uma limitação aos movimentos devido à posição ou à delicadeza das estruturas e, portanto houve a necessidade de adaptar-se a maneira de executar o nó, com as necessidades específicas do cirurgião, permitindo padronização e segurança, para realizar qualquer procedimento cirúrgico.

Os nós consistem no cruzamento dos fios, formando uma laçada e na passagem de um dos fios através dessa laçada e, então, com um fio de cada lado pode-se aproximá-los, fechando a laçada (Figura 7).

A diferença entre um nó comum e um nó utilizado em procedimento cirúrgico é a maneira como se passa o fio através da laçada. Notem, na fig 1 que o fio branco entra pela laçada à direita e sai à esquerda e que no próxima laçada o fio brando entra pela es-

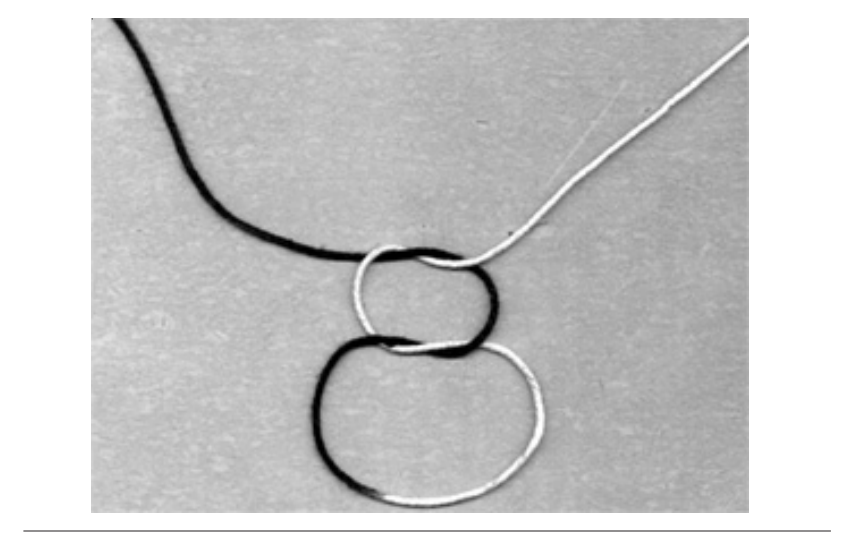

Figura 7: Princípio básico de um nó.

querda e sai pela direita. Neste detalhe se baseia a técnica utilizada pelos cirurgiões para realizar os nós.

A posição das mãos e a escolha do dedo que irá executar o nó depende de como o fio deve fechar a laçada. Ressalta-se que o nó realizado sem se preocupar com este detalhe pode se tranformar em uma zona de fraqueza, com o risco de se romper durante o procedimento cirúrgico ou após terminada a cirurgia causando deiscência da ferida operatória.

Os nós podem ser realizados com uma ou duas passagens pela mesma laçada. $\mathrm{O}$ com uma passagem 
apenas é um nó deslizante, pois pode-se reajustar a tensão, mesmo depois de realizado. O nó com duas passagens pela laçada, não desliza, e portanto é utilizado quando não se deseja ou não pode haver afrouxamento do primeiro nó. È utilizado para aproximação de estruturas sob tensão (Figura 8)
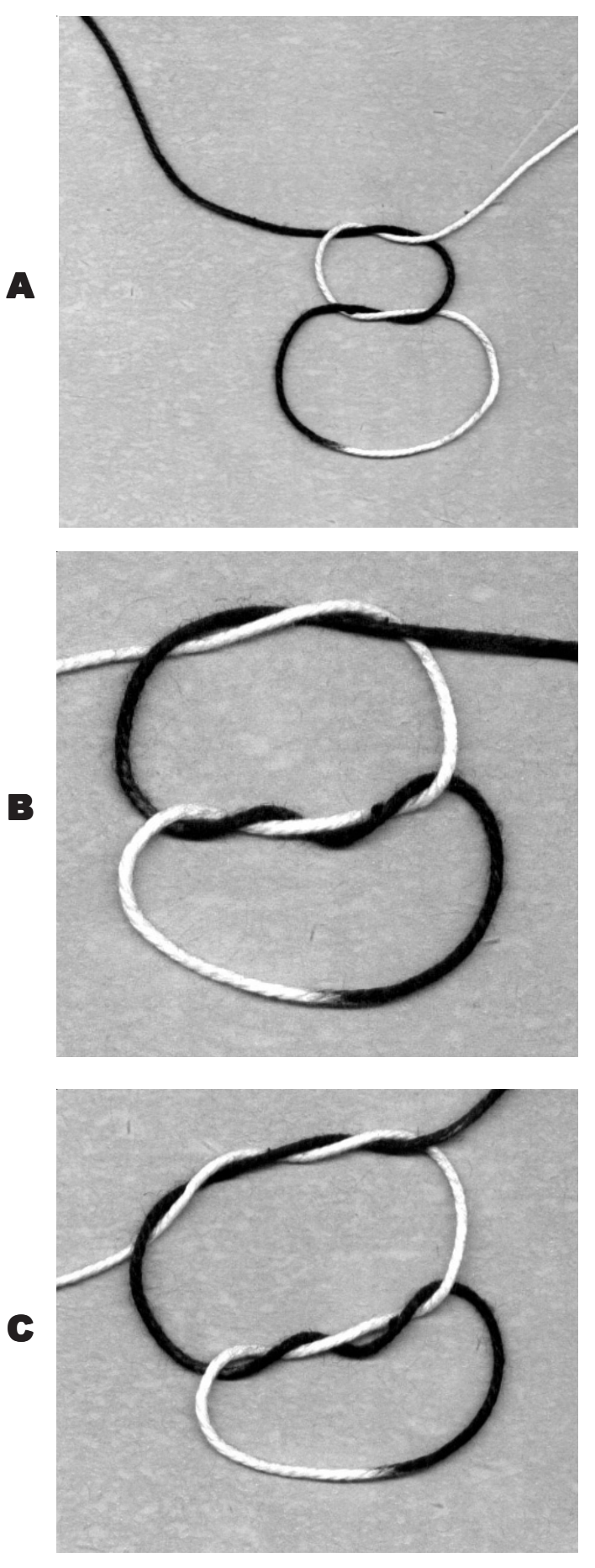

Figura 8: a) nó comum, b) primeiro nó com laçada dupla e segundo nó com laçada simples,c) os dois nós com laçada dupla.
Quando se realizam suturas contínuas, existe uma peculiaridade na execuçao do primeiro nó, pois ele não pode permanecer entre as bordas da ferida.

Portanto existe um nó utilizado especificamente para este fim, como apoio para a sutura, tanto no seu início como término e, como ele é deslizante, pode ser ajustado à tensão da sutura (Figura 9).

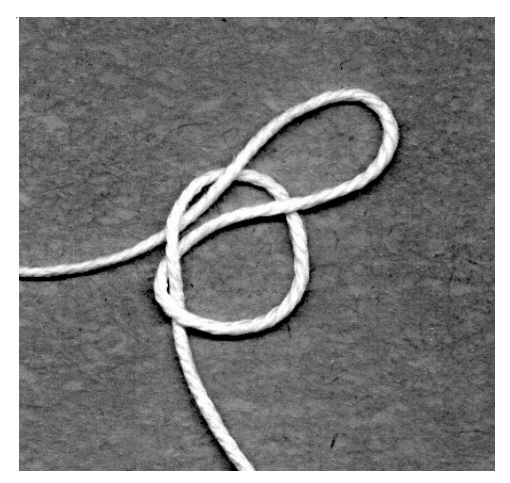

Figura 9: nó utilizado em suturas contínuas

Quando existe tensão entre as bordas da ferida, pode-se usar o nó de sapateiro, segurando-se as pontas do fio, no local onde se cruzam e passando o fio por dentro da laçada de cima para baixo, de maneira semelhante ao nó utilizado para amarrar os sapatos (Figura 10).
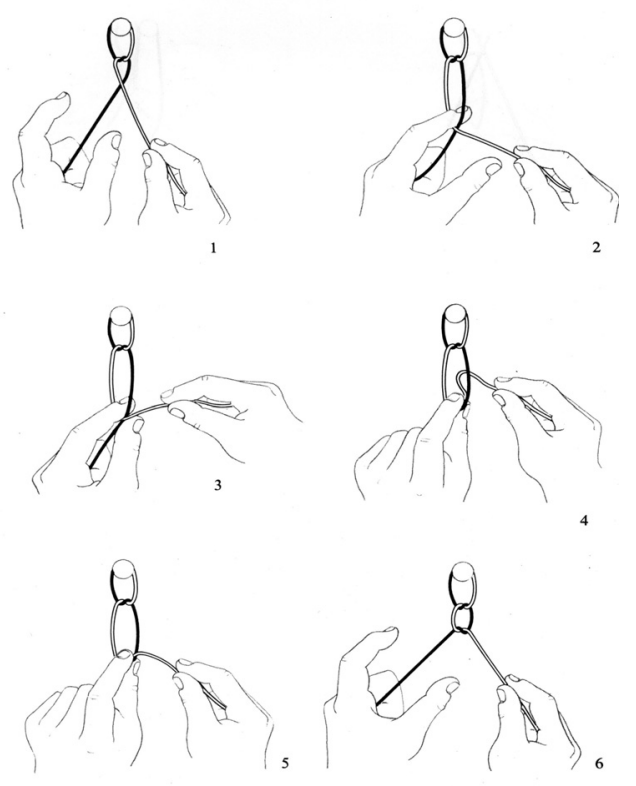

\footnotetext{
Figura 10: Nó de sapateiro
} 
Pode também ser utilizado, quando se depara com a tensão aumentada entre as bordas da ferida, o nó de cirurgião. Na Figura 11 demontra-se o cruzamento do fio, a escolha de qual dedo irá pinçar o fio e a realização da dupla laçada, ao mesmo tempo, utilizando-se o dedo médio no fio que está passando por baixo dos fios cruzados e o dedo indicador para o de cima.
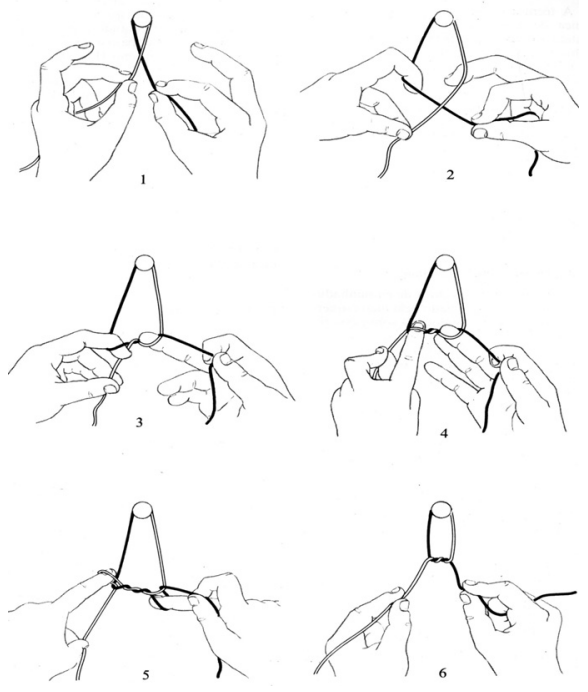

Figura 11: nó do cirurgião

Muitas vezes o cirurgião se vê, em um determinado momento, com um fio curto para dar o nó. Neste caso ele pode usar um instrumento halsted reto ou o próprio porta agulhas para efetuar o nó (Figura 12).

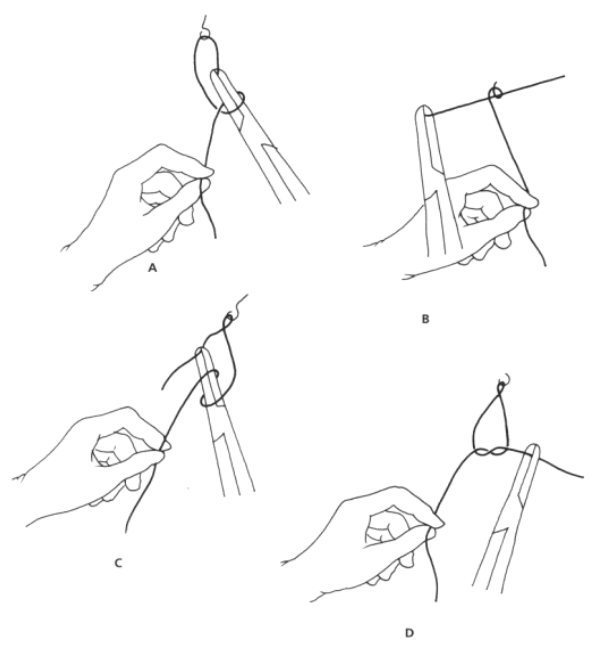

Figura 12: nó com instrumento
Um outro tipo de nó, muito utilizado é o nó de apoio das suturas contínuas, principalmente das suturas intradérmicas.

Conforme o demonstrado na Figura 13, observa-se a realização da laçada, com o porta agulha e a passagem do fio através dela, formando uma ponta que pode ser amarrada mais uma vez, se necessário.

Com esta laçada, inicia-se a sutura contínua e quando ela terminar repete-se o mesmo procedimento, para formar uma nova laçada.
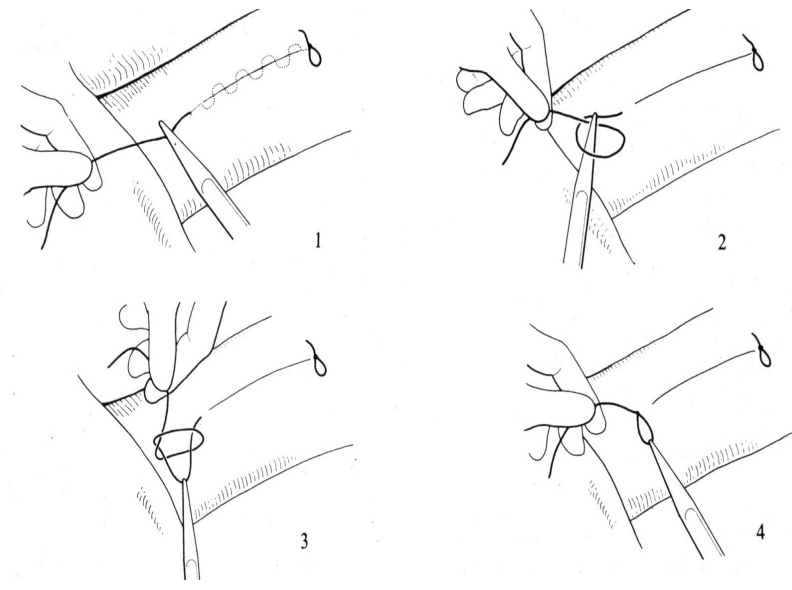

Figura 13: nó de apoio às suturas contínuas

Observando as figuras 14 e 15 nota-se o detalhe da entrada no fio na laçada e qual o dedo a ser utilizado para realizar o nó.

O primeiro passo consiste em cruzar os fios. Este passo é muito importante pois neste momento observa-se como a laçada será formada e qual a posição dos fios. De acordo com a figura 14, o fio branco passa por cima do preto. Se o cirurgião quer usar a mão esquerda, ele utilizará a palma da mão para abaixar o fio que se encontra abaixo (o preto) e assim conseguir uma laçada, como mostra a figura 14. A seguir, com o dedo médio o fio é pinçado, passado por dentro da laçada, de cima para baixo e, então, com um fio em cada mão fecha-se laçada.

$\mathrm{Na}$ figura 15, observa-se, ao cruzar o fio, que o fio preto está passando por cima do fio branco. Se o cirurgião quer usar a mão esquerda, ele utilizará o dedo indicador para levantar o fio que está paasando por cima ( o fio branco) e assim conseguir uma laçada. A seguir, com o dedo indicador o fio é pinçado, passado por dentro da laçada, de baixo para cima e, então, com um fio em cada mão fecha-se laçada. 

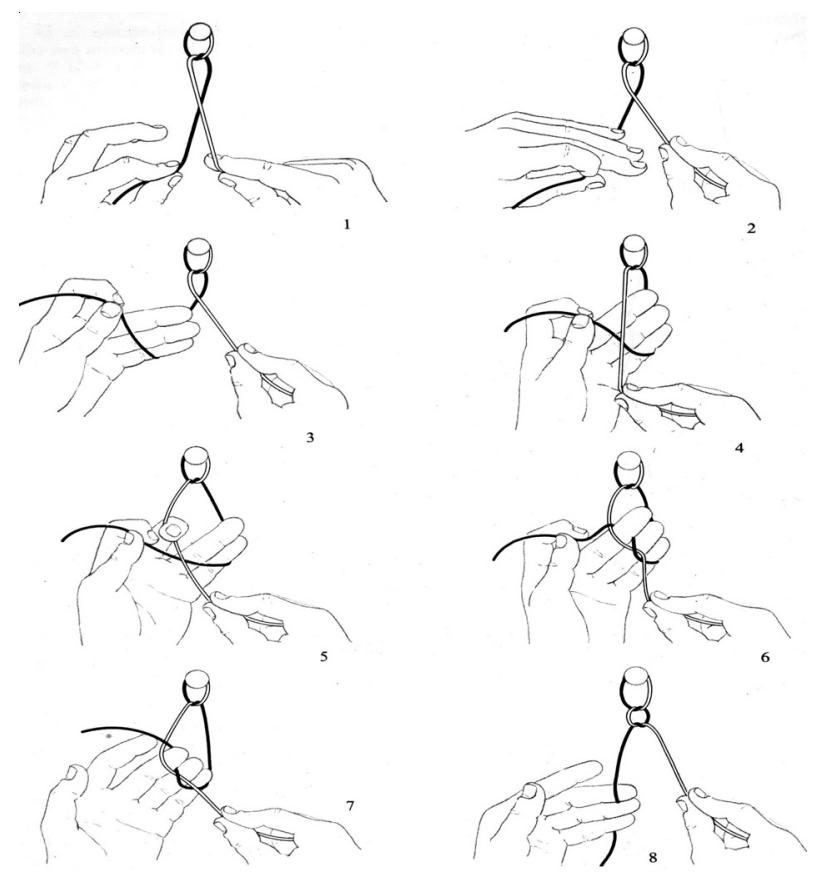

Figura 14: Utilização do dedo médio.
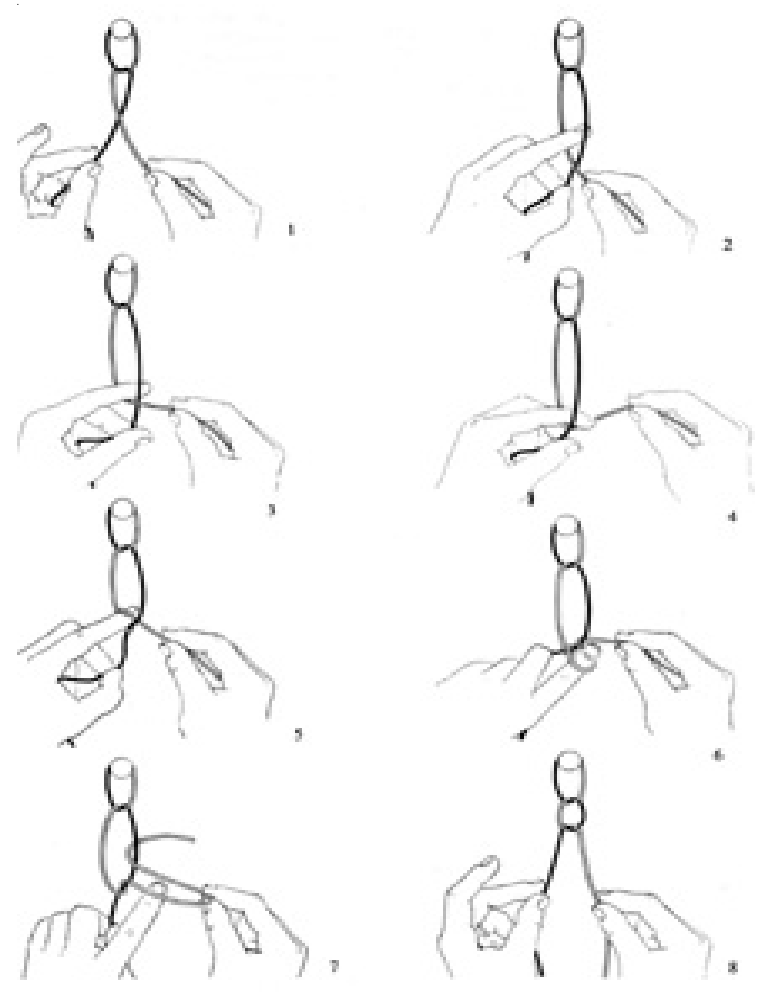

Figura 15:

\section{Suturas}

As agulhas cirúrgicas, utilizadas na síntese, penetram e atravessam os tecidos e, assim, conduzem os fios para os locais adequados. As agulhas, para melhor conforto e praticidade são montadas na ponta de um porta agulha, e na metade da agulha.

As agulhas, conforme o seu ângulo interno, podem ser classificadas em curvas (ângulo interno de 180 graus), semi retas (ângulo interno menor que 180 graus) e retas.

De acordo com a secção transversal da ponta, as agulhas dividem-se em cilíndricas, triangulares e prismáticas (Figura 16 e 17). Dependendo do tipo da ponta, as agulhas são classificadas em traumáticas, com pontas triangular ou prismática e traumática quando cilíndricas.

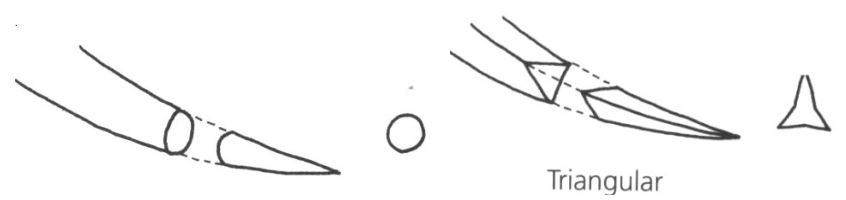

Cilíndrica

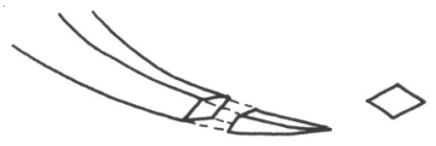

Prismática

Figura 16: Tipos de agulhas de acordo com a secção transversal.
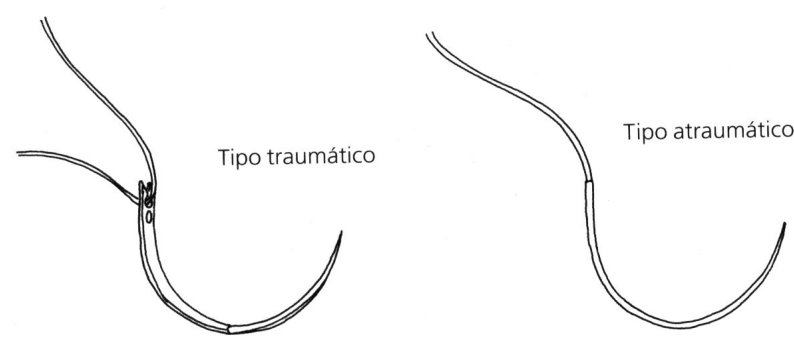

Figura 17: Agulhas traumáticas e atraumáticas.

As agulhas de sutura foram projetadas para penetrar e transpassar os tecidos levando, através destes, fios de sutura. Conforme a forma do corpo da agulha e de sua ponta, diferentes tipos de lesões serão produzidos nos tecidos. Portanto a escolha da agulha depende da estrutura a ser suturada. 
A realização de sutura para o fechamento de incisões ou de ferimentos visa evitar infecção, obter resultado estético satisfatório e promover cicatrização da ferida com maior rapidez e segurança e, assim, garantir o sucesso do ato operatório.

Para se realizar uma sutura adequada faz-se necessário introduzir a agulha perpendicularmente à estrutura a ser suturada (Figura 18), a quantidade de tecido englobada pela agulha deve ser semelhante em ambas as bordas da ferida para assegurar uma aproximação adequada; deve-se atentar para a espessura do tecido a ser suturado, pois quanto mais espessa for, mais grosso deve ser o fio e maior a quantidade de tecido a ser englobada pela agulha.
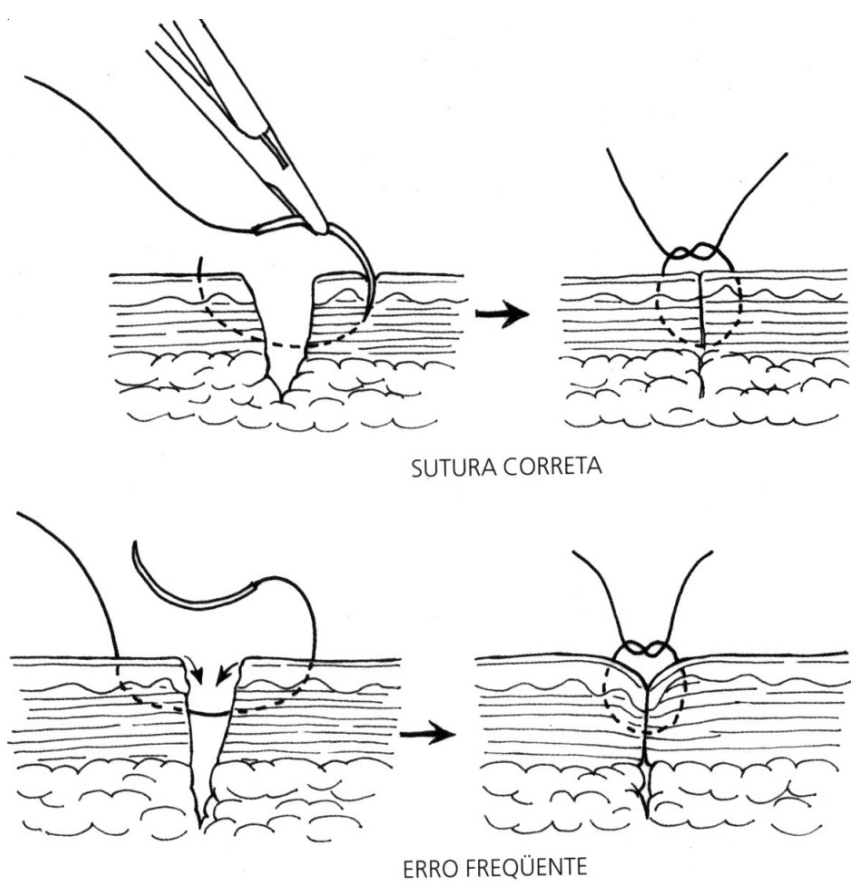

Figura 18: (A) Forma correta: agulha penetrando perpendicularmente e a englobando a mesma quantidade de pele dos dois lados. (B) Forma incorreta: ponto pouco profundo e conseqüente retração da pele.

A tensão exercida pelo nó não deve ser excessiva, pois pode causar necrose tecidual e mau resultado estético, devido a aumento do tecido cicatricial. Por outro lado, se estiverem muito frouxos, deixam espaço para a formação de tecido de granulação entre as bordas da ferida, acarretando cicatrização por segunda intenção.

A presença de espaço morto ao redor do nó causar deiscência, infecção e aderência (Figura 19) A tensão ideal dos nós permite a passagem da ponta de uma pinça de Halsted sob o fio, com facilidade.

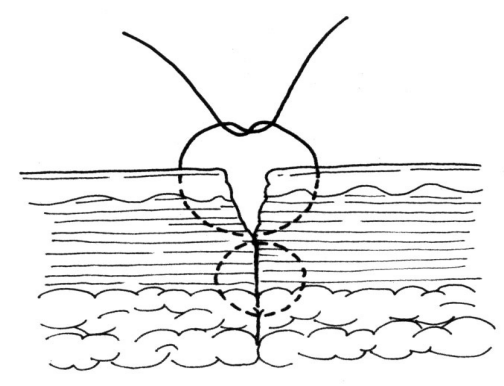

Figura 19: Sutura em dois planos, um superficial e um profundo, para evitar o espaço morto.

Para um resultado ainda mais estético, nas suturas de pele, deve se seguir as linhas de força de Kraissl. Estas linhas correspondem às áreas de menor tensão da superfície corporal, quando da realização de incisões e suturas da pele. A figura 20 corresponde às linhas de Kraissl nas faces anterior e posterior do homem.
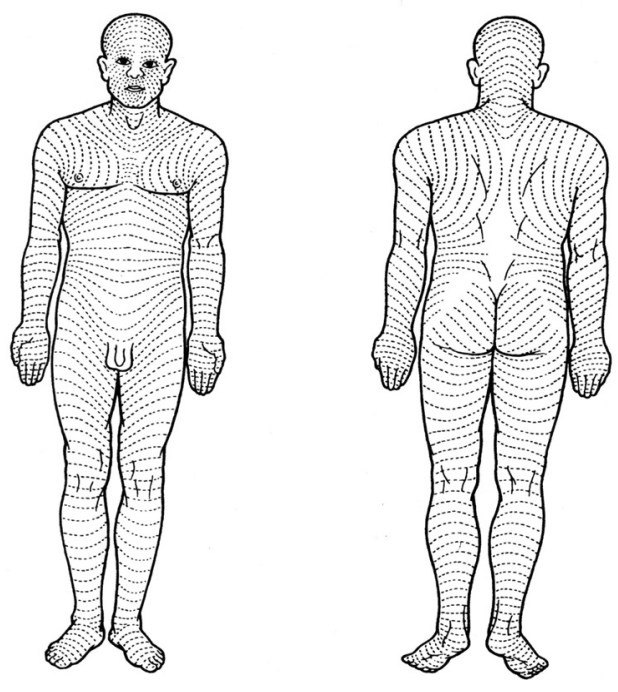

Figura 20: Linhas de KraissI na face anterior e na face posterior do corpo humano.

A cicatrização inadequada e a probabilidade aumentada de ocorrer deiscência, estão associadas a uma série de fatores: tensão excessiva das bordas da ferida ou dos nós, retirada prematura dos pontos, deficiências nutricionais, doenças degenerativas e do colágeno, medicamentos, falha técnica e presença de infecção, coágulos, seroma, material sintético. Outra complicação são as cicatrizes hipertróficas e alargadas, chamadas quelóides, que ocorrem quando o paciente apresenta defeito no mecanismo da cicatrização. 
Realiza-se a síntese dos ferimentos através de suturas, grampos metálicos e colas adesivas. As suturas podem ser realizadas com pontos simples, contínuo e intradérmico. As suturas intradérmicas produzem cicatrizes mais estéticas e, também tem a vantagem de não se retirar os pontos. As suturas podem ser executadas em um ou mais planos, dependendo da profundidade e espessura das estruturas a serem suturadas.

Em geral, a agulha deve ser introduzida próxima às margens da ferida, assim como deve ocorrer na sua saída, o que evita marcas permanentes sobre a superfície cutânea, em especial, no caso de retirada tardia dos pontos.

Como opção de sutura cutânea que oferece bom resultado estético utilizam se, uitas vezes, os pontos simples separados (Figura 21) ressalta-se a entrada da agulha em um ponto eqüidistante da saída da agulha até a borda da ferida. A distância entre os pontos acompanha a distância entre a borda da pele e a entrada da agulha. Os nós amarrados sem tensão excessiva e dispostos lateralmente à incisão, facilitam a cicatrização.

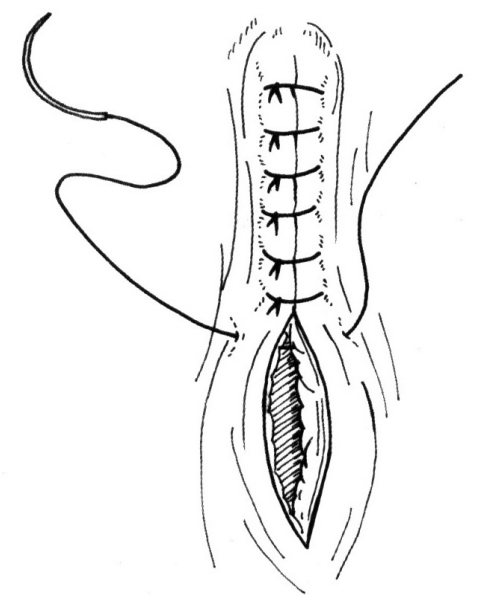

Figura 21: Técnica de pontos simples separados.

Outro tipo de sutura bastante comum é a de pontos separados em U vertical (pontos de Donati), que além de aproximar as bordas da ferida, também realizam a hemostasia de vasos sangrantes (Figura 22) - técnica de fechamento "perto-longe".

A sutura contínua em chuleio é muito utilizada e pode ser intradérmica, quando os pontos são dados na borda interna da ferida (Figura 23 e 24).

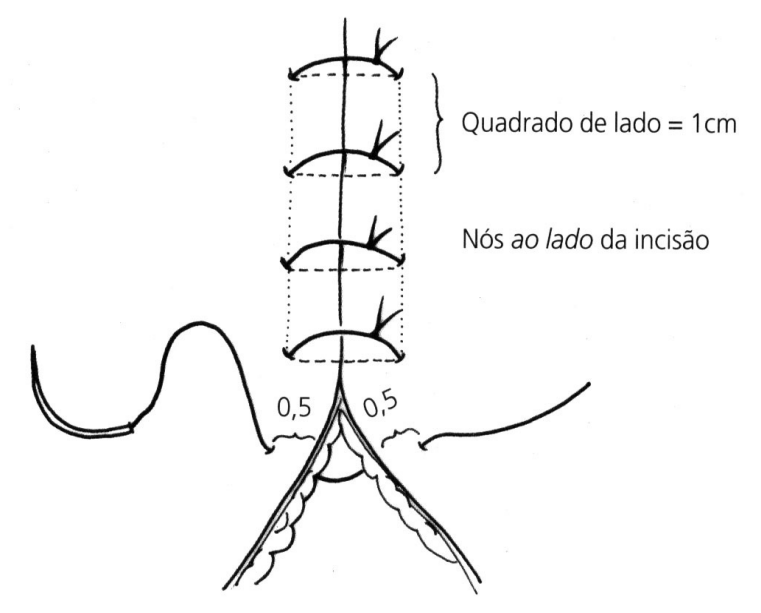

Figura 22: Sutura com pontos separados verticais em $\mathrm{U}$, conhecida como pontos de Donati.

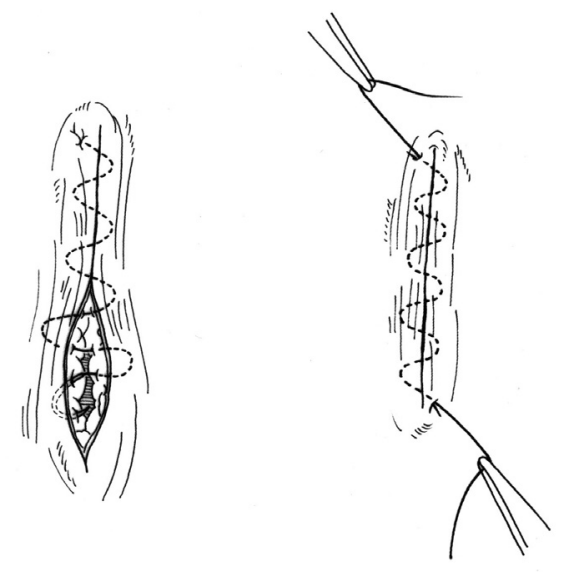

Figura 23: Sutura contínua em chuleio.
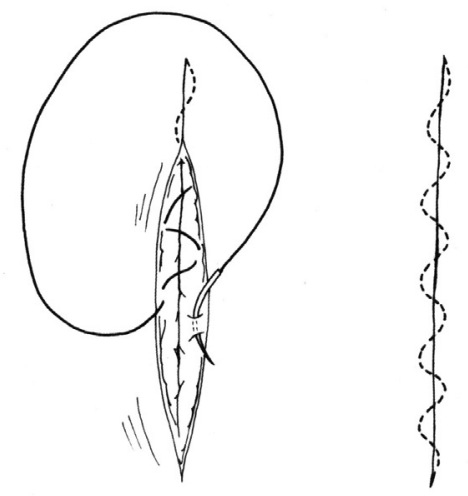

Figura 24: Sutura intradérmica.

Os fios de sutura devem ser mantidos até que a cicatrização se efetue e possa manter as bordas da ferida justapostas. Isto ocorre ao redor do sétimo dia, quando o paciente for hígido e quando se utiliza a técnica cirúrgica correta. 


\section{Retirada dos fios de sutura cutânea}

Os fios de sutura devem ser mantidos apenas enquanto forem úteis, não sendo lógica afixação de prazos para a retirada dos pontos. Como norma, deve ser retirada o mais breve possível, logo que a cicatriz adquira resistência. A experiência do cirurgião, no entanto servirá para decidir a época oportuna. Os elementos que devem ser levados em conta para avaliação são:

a. aspecto da cicatrização se está seca, sem edema ou congestão;

b. local da ferida se tem tensões excessivas sobre a cicatriz;

c. direção da cicatriz se obedece a linha de força.

d. condições favoráveis para a cicatrização.

\section{Hemostasla}

A hemostasia tem por objetivo impedir ou coibir a hemorragia durante o ato operatório. Evita a perda excessiva de sangue, propicia uma cirurgia limpa com melhores condições técnicas, aumenta o rendimento do trabalho e repercuti na duração do ato operatório e na evolução-recuperação pós-operatória, evitando formação de hematomas no pós-operatório, infecção e deiscência e conseqüentemente reoperações desnecessárias.

\section{Tipos de Hemostasia}

A a hemostasia pode ser temporária ou definitiva, preventiva ou corretiva.

\section{Temporária}

É executada no campo operatório (cruenta) ou à distância do mesmo (incruenta) e podem ser dos seguintes tipos:

\section{a- Pinçamento}

É um método cruento. A hemostasia poderá se tornar definitiva posteriormente por ligadura, cauterização ou angiotripsia. Em cirurgias de revascularização, utiliza-se rotineiramente pinças específicas, que praticamente não lesam o endotélio vascular, pois são atraumáticas, e, portanto não provocam a trombose.

A hemostasia é preventiva quando se faz antecipadamente o pinçamento do vaso a montante e a jusante do local da secção vascular e ela se torna corretiva quando o pinçamento é realizado após a lesão vascular, quando já se instalou o sangramento.

\section{b- Compressão}

Ela pode ser cruenta quando realizada no campo operatório ou incruenta quando feita sem previa diérese ou à distancia do campo operatório. Quando à distância pressiona-se o trajeto do vaso, geralmente com o dedo polegar contra uma superfície óssea. No campo operatório a compressão pode ser efetuada pelo pinçamento digital com o polegar e dedo indicador.

\section{c- Garroteamento}

Geralmente é um método incruento. Pode ser usada faixa de Smarch, manguito de pressão etc. Tem suas limitações e contra-indicações.

\section{d- Ação farmacológica}

A hemostasia por ação farmacológica local se obtém por injeção de substâncias, que causam vasoconstrição e consequientemente diminuem o sangramento no local da cirurgia, ou por aplicação tópica. Geralmente necessita de outro tipo de hemostasia complementar para solução do problema.

\section{e- Parada circulatória com hipotermia}

É um método sofisticado de hemostasia temporária, de aplicação limitada, porém de indubitável valor. Consiste em colocar o paciente em extracorpórea para se evitar sangramento e em hipotermia para minimizar os danos da parada circulatória prolongada.

\section{f- Oclusão endovascular}

É utilizado principalmente nas reintervenções sobre artérias, para evitar pinçamento externos em condições adversas. O procedimento consiste na introdução de um balão na luz da artéria bloqueando o fluxo de sangue.

\section{Definitiva}

Geralmente é feita de modo cruento e interrompe definitivamente a circulação do vaso sobre o qual é aplicada e pode ser:

\section{a- Ligadura}

É a amarração dos vasos com fios cirúrgicos. Pode ser preventiva ou corretiva.

\section{b- Cauterização}

Promove a formação de um coágulo na extremidade sangrante com a aplicação de agentes físicos como calor, eletricidade ou substâncias químicas e está sempre limitado ao calibre do vaso. 


\section{c- Sutura}

Certas suturas são feitas englobando vasos com finalidade hemostática. Exemplos: suturas totais de anastomoses gastrointestinais e as suturas de lesões de grandes vasos.

\section{d- Obturação}

Aplica-se substancias exógenas para ocluir a luz do vaso sangrante. Exemplo: cera óssea para hemostasia nos sangramentos ósseos difusos.

\section{e- Tamponamento}

Realiza-se pela compressão de área sangrante com compressa ou gaze. É medida excepcional a ser adotada em hemorragia venosas ou capilares de superfície, quando outros recursos foram infrutíferos.

\section{f- Grampeamento}

É um tipo de hemostasia definitiva através do uso de grampos metálicos - aço inoxidável ou titânio muito empregada atualmente em cirurgias vídeo-endoscópicas.

\section{ABSTRACT}

Distinct instruments are employed during the accomplishment of each of the stages of a surgical procedure. For the surgeon to perform the procedure accurately and efficiently, order and method are mandatory. To this end, surgical instruments should be listed and prepared well in advance, according to the surgery type and the surgeon's preferences
\end{abstract}

Keywords: Surgical Instruments. Surgical Material. Surgical Technique. Surgical Procedures, Operative.

\section{Bibliografia recomendada}

1. Cirino LMI. Instrumental cirúrgico e operações fundamentais. In: Cirino LMI: Manual de técnica cirúrgica para a graduação. São Paulo: Sarvier; 2006. p.13.

2. Goffi FS, Tolosa EMC. Operações fundamentais. In: Goffi FS. Técnica cirúrgica: bases anatômicas e fisiopatológicas e técnicas da cirurgia. $4^{a}$ ed. Rio de Janeiro: Atheneu; 2001. p.52-3.

3. Magalhães HP. Técnica cirúrgica e cirurgia experimental. São Paulo: Sarvier; 1993.

4. Tolosa EMC, Pereira PRB. Diérese. In: Goffi FS. Técnica cirúrgica: bases anatômicas e fisiopatológicas e técnicas da cirurgia. $4^{a}$ ed. Rio de janeiro: Atheneu, 2001. p. 54-61.
5. Tolosa EMC, Pereira PRB. Hemostasia. In: Goffi FS. Técnica cirúrgica: bases anatômicas e fisiopatológicas e técnicas da cirurgia. 42 ed. Rio de janeiro: Atheneu, 2001. p. 62-6.

6. Tolosa EMC, Carnevale J, Pereira PRB. Síntese cirúrgica. In: Goffi FS. Técnica cirúrgica: bases anatômicas e fisiopatológicas e técnicas da cirurgia. Rio de janeiro: Atheneu, 2001. p. 67-74.

7. Goffi FS. Técnica cirúrgica: bases anatômicas, fisiopatológicas e técnica cirúrgica. Atheneu: 1978.

8. Magalhães HP. Técnica cirúrgica e cirurgia experimental. São Paulo: Sarvier, 1993. 